\title{
Transverse cervical skin incision and vertical platysma splitting approach for anterior cervical vertebral column exposure
}

\author{
Amit Agrawal, G. Malleswara Rao \\ Professors of Neurosurgery, Department of Neurosurgery, Narayna Medical College \\ Hospital, Chinthareddypalem, Nellore, Andhra Pradesh (India)
}

\begin{abstract}
Anterior surgical approaches provide direct access to symptomatic areas of the cervical spine, allow management of the vast spectrum of cervical spine pathologies and there are many articles in the literature that discussed these techniques in detail. Cosmesis is an important issue for patients who undergone surgeryon neck structures as an improperly placed incision attracting significant morbidity and few publications discuss this issue in details. The purpose of the present article is to describe our experience with transverse cervical skin incision and vertical platysma splitting approach for anterior cervical vertebral column exposure.
\end{abstract}

Key words: cervical spine, neck incision, platysma, cosmesis, anterior cervical discectomy, cervical fusion.

\section{Introduction}

Anterior surgical approaches provide direct access to symptomatic areas of the cervical spine, allow management of the vast spectrum of cervical spine pathologies and there are many articles in the literature that discussed these techniques in detail. $(1,2)$ Cosmesis is an important issue for patients who undergone surgeryon neck structures as an improperly placed incision attracting significant morbidity and few publications discuss this issue in details. (3-7) The purpose of the present article is to describe our experience with transverse cervical skin incision and vertical platysma splitting approach for anterior cervical vertebral column exposure.

\section{Material and methods}

A total 56 patients were treated for cervical spine disease through anterior cervical approach. All patients had lesions in the upper neck, and all the lesions were preoperatively diagnosed by MRI scans. Informed consent was approved by the insti $\neg$ tutional review board and obtained from all patients in this study. The patients underwent surgery with diagnostic or curative intents.

\section{Surgical Technique}

Under general anesthesia, the head of patient was rotated to the opposite side, and the neck was extended by placing a pillow under the upper chest. Surgery was performed by the same consultant surgeon using standard techniques of neck dissection. The site of lesions informed by 
preoperative MRI scans and physical examination was delineated, and a skin incision was marked on right side of the neck in all patients (Figure $1 \mathrm{~A}$ ). The patient was placed in the supine position with the head in slight extension and turned to left. A transverse skin crease incision was made in all patients; the length of the incision was determined by the extent of vertical exposure.The incision was started from the midline anteriorly and extended laterally just over anterior one third of sternomastoid (Figure A-F). The incision was carried down through the subcutaneous fat onto the platysmamuscle, and the flap was elevated by creating a plane between subcutaneous flap and platysma muscle by blunt and sharp dissection (Figure 2 A-F). Platysma was split vertically along the direction of its fibers (Figure $2 \mathrm{C}$ ). Standard procedure to create an avascular dissection plane was followed to develop between the esophagus/trachea, medially, and the sternocleidomastoid/ carotid sheath, laterally. (8-12) Hand held retractors were utilized to provide initial exposure of the anterior vertebral column and the adjacent longuscolli muscles. The other procedures for management of lesions were as per the standard indications.Briefly, following apposition of the strap muscles of the neck and closure of platsyma and skin incision was performedwith continuous subcutaneous sutures using 4-0 Vicryl (Figure 3 A-C). All patients received a standard postoperative protocol and analgesic regimen to achieve tolerance of

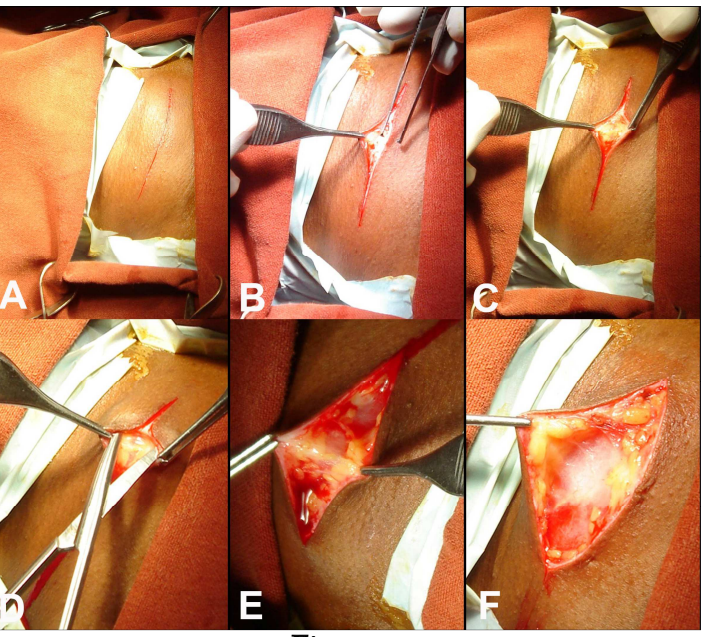

Figure 1

(A) Cervical incision marking, (B) Incision through subcutaneous fat, (C) Subcutaneous fat plane exposure, (D) Dissection through subcutaneous fat, (E) Creating plane between skin flap and platysmaand (F) Creating plane between skin flap and platysma

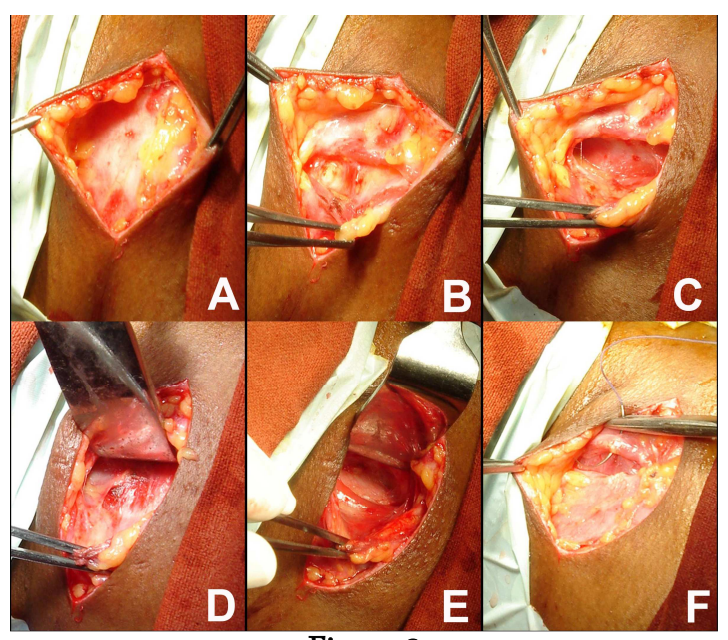

Figure 2

(A) Creating plane between skin flap and platysma, (B) Platysma split vertically along muscle fibers, (C) Creating plane between esophagus/trachea medially and carotid laterally, (D) Creating plane between esophagus/trachea medially and carotid laterally, (E) Creating plane between esophagus/trachea medially and carotid laterally and (F) Approximating platysma edges fluids and diet prior to discharge. 


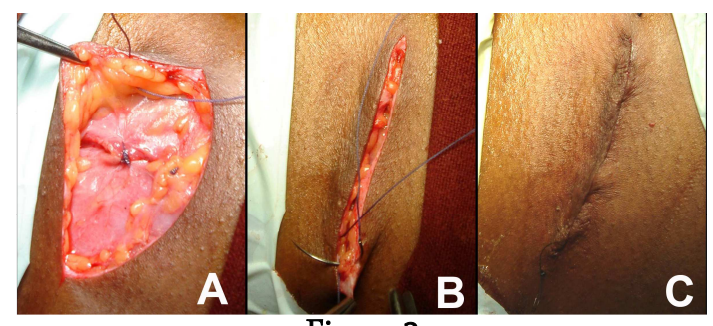

Figure 3

(A) Approximating platysma edges, (B) Closure with subcutaneous sutures and (C) Closure with subcutaneous sutures

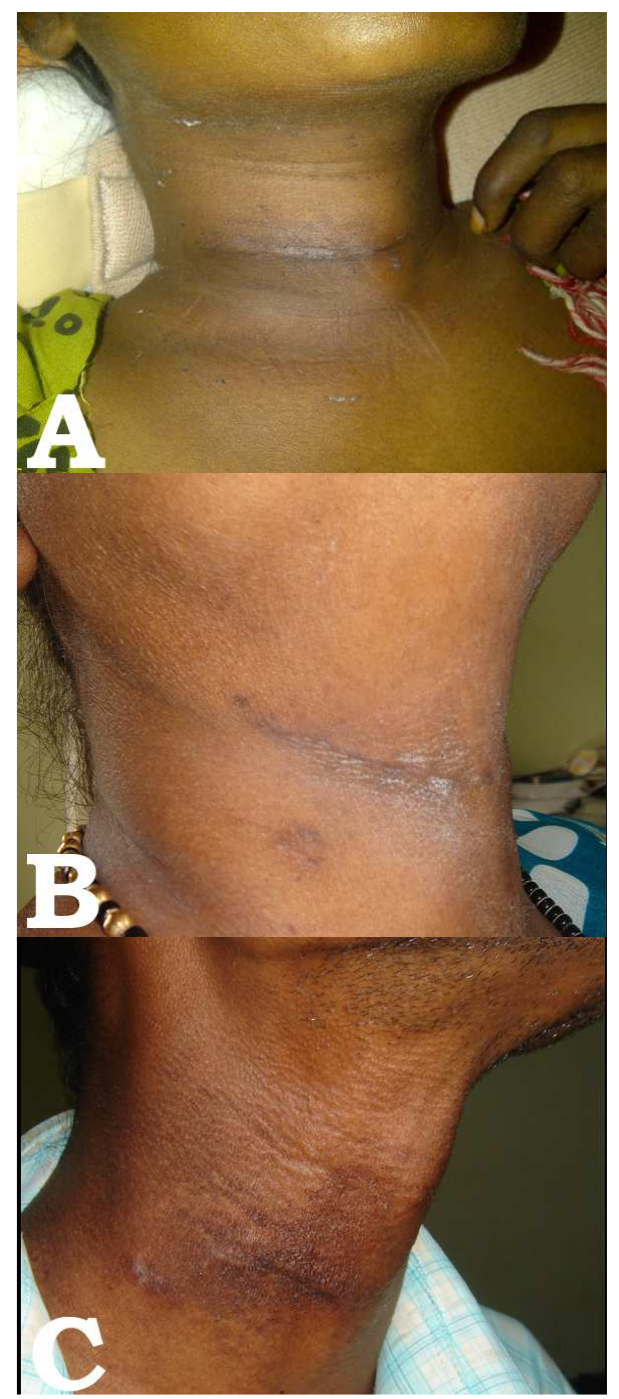

Figure 4

(A, B and C) Showing follow-up images with good cosmetic outcome

\section{Results}

All the patients were followed with careful examinations of the wound and it healed well in all. There were no incidences of wound infection, flap necrosis or wound gaping (Figure $4 \mathrm{~A}-\mathrm{C}$ ).

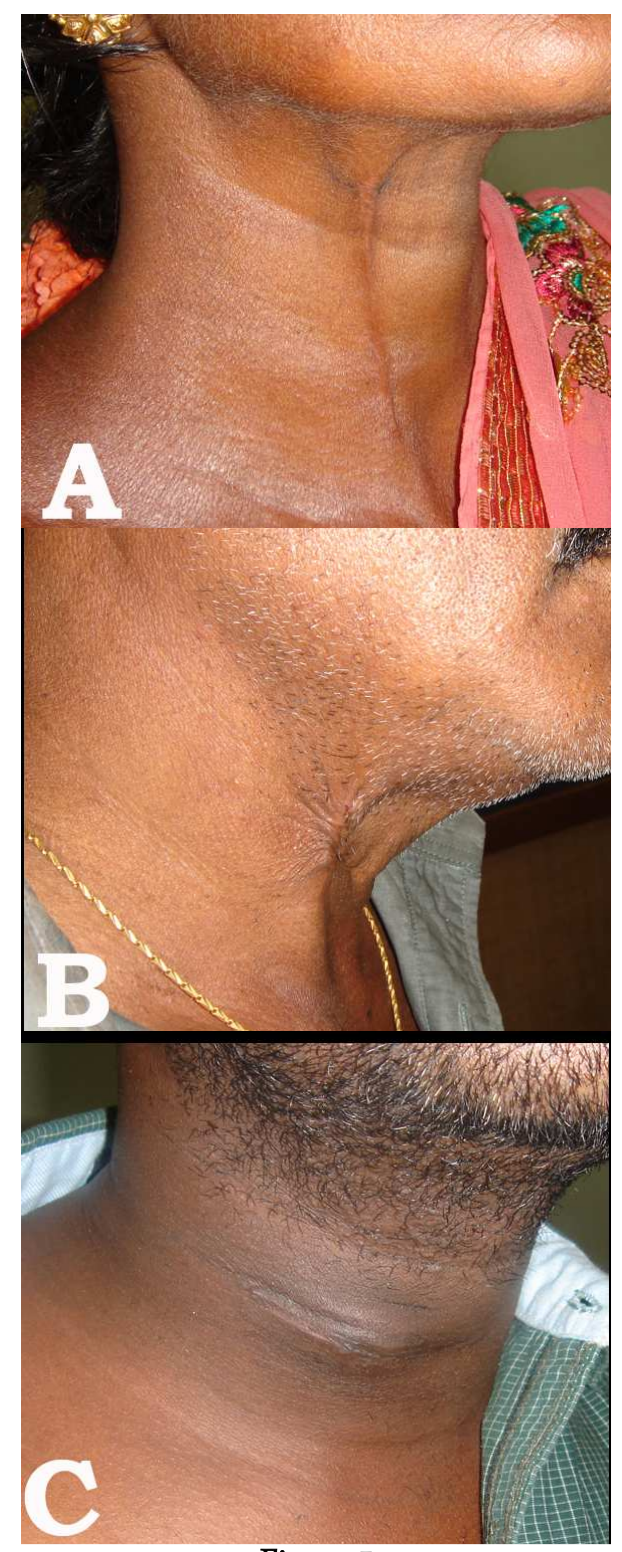

Figure 5

(A, B and C) Cutting the platysma can be associated with puckering of the skin and poor cosmetic results 


\section{Discussion}

Anterior cervical approaches has been described as most appropriate in patients with decompression of the cervical spine and nerve roots as it allows safe and direct decompression of the spinal cord at the site of compression. $(8,13)$ The surgical technique has been well discussed and has evolved one of the most popular spinal surgery operations over the past century. (8-10) In anterior cervical approach, the vertebral column is approached through a transversal or vertical cervical incision and the cervical spine is reached between the trachea and oesophagus medially, and the carotid-jugular group laterally. $(1,2,11$, 12, 14-16) Platysma muscle can be cut (11) or split (17) in line with the skin incision to expose the anterior border of sternomastoid muscle. However cutting the paltysma may be associated with puckering and poor scar formation (Figure

$5 \mathrm{~A}, \mathrm{~B}$ and $\mathrm{C}$ ). There is growing enthusiasm for the use of smaller incisions in head and neck region with better cosmetic outcome while following the application of well-known cosmetic principles and achieving optimum and safe exposure of area of interest. $(18,19)$ There has been increasing concern about cosmesis and invisible postoperative scars of the face and neck $(18,20-23)$ as the face and neck are considered as the most important parts of human body in terms of beauty. (19) Cutting of platysma may result in puckering of skin and cosmetic concern to the patient. Also the final cosmetic appearance of a neck wound is also of great importance to patients as the wound is likely to be permanently on view.

\section{Conclusions}

Skin closure technique is aimed to precisely oppose the skin edges without tension for sufficient time to allow healing to take place. (23) It has been proposed that skin closer in the sagittal plane, more aligned with Langer's lines for a 'neck-line' incision results in a more aesthetic outcome. (24) We followed this in present study to achieve cosmetically acceptable scar in the neck. The present surgical incision allowed splitting of platysma (in contrast to cutting in line of skin incision), adequate exposure of the cervical spine and cosmetically acceptable scar in the neck.

Address for correspondence:

Dr Amit Agrawal

Professor of Neurosurgery

Department of Neurosurgery

Narayna Medical College Hospital

Chinthareddypalem

Nellore-524003

Andhra Pradesh (India)

Email:dramitagrawal@gmail.com dramit_in@yahoo.com

Mobile: $+91-8096410032$

\section{References}

1. Denaro V, Di Martino A. Cervical spine surgery: an historical perspective. Clinical orthopaedics and related research 2011;469:639-648.

2. Fransen P. A simplified technique for anterior cervical discectomy and fusion using a screw-plate implanted over the Caspar distractor pins. Acta orthopaedica Belgica 2010;76:546-548.

3. Ready AR, Barnes AD. Complications of 
DOI: 10.2478/romneu-2014-0010

thyroidectomy. The British journal of surgery 1994;81:1555-1556.

4. Bartel M, Rupprecht H, Schubert H. Mediastinoscopy and scar-keloid's in boeck's sarcoid (author's transl)]. Zeitschrift für Erkrankungen der Atmungsorgane 1976;145:388.

5. Eldridge PR, Wheeler MH. Stitch granulomata after thyroid surgery. The British journal of surgery 1987;74:62.

6. Jancewicz S, Sidhu S, Jalaludin B, Campbell P. Optimal position for a cervical collar incision: a prospective study. ANZ journal of surgery 2002;72:1517.

7. Ridgway DM, Mahmood F, Moore L, Bramley D, Moore PJ. A blinded, randomised, controlled trial of stapled versus tissue glue closure of neck surgery incisions. Annals of the Royal College of Surgeons of England 2007;89:242-246.

8. Moran C, Bolger C. Operative techniques for cervical radiculopathy and myelopathy. Advances in orthopedics 2012;2012:916149.

9. Cloward RB. Lesions of the intervertebral disks and their treatment by interbody fusion methods. The painful disk. Clinical orthopaedics and related research 1963;27:51-77.

10.Smith GW, Robinson RA. The treatment of certain cervical-spine disorders by anterior removal of the intervertebral disc and interbody fusion. The Journal of bone and joint surgery American volume 1958;40-A:607624.

11.Patnaik V, Singla Rajan K, Gupta P, Bala S. Surgical Incisions-Their Anatomical Basis Part V-Approaches to spinal column. J Anat Soc India 2002;51:76-84.

12.Kavanagh RG, Butler JS, O'Byrne JM, Poynton AR. Operative techniques for cervical radiculopathy and myelopathy. Advances in orthopedics 2012;2012:794087. 13.Hilibrand AS, Carlson GD, Palumbo MA, Jones PK, Bohlman HH. Radiculopathy and myelopathy at segments adjacent to the site of a previous anterior cervical arthrodesis. The Journal of bone and joint surgery American volume 1999;81:519-528.

14.Crenshaw A. Campbell's operative orthopaedics,
Mosby, St. Louis, MO 1992:1681-1683.

15.Abbott KH. ANTERIOR CERVICAL DISC REMOVAL AND INTERBODY FUSION. A PRELIMINARY REVIEW OF 101 PATIENTS FOLLOWED FOR ONE TO THREE YEARS. Bulletin of the Los Angeles Neurological Society 1963;28:251259.

16.Lied B, Roenning PA, Sundseth J, Helseth E. Anterior cervical discectomy with fusion in patients with cervical disc degeneration: a prospective outcome study of 258 patients (181 fused with autologous bone graft and 77 fused with a PEEK cage). BMC surgery 2010;10:10.

17.Mayer HM, Siepe C, Korge A. [The microsurgical anterior approach for total cervical disc replacement]. Operative Orthopadie und Traumatologie 2010;22:454467.

18.Terris DJ, Seybt MW, Elchoufi M, Chin E. Cosmetic thyroid surgery: defining the essential principles. The Laryngoscope 2007;117:1168-1172.

19.Maillard GF, Clavel PR. Aesthetic units in skin grafting of the face. Annals of plastic surgery 1991;26:347-352.

20.Roh JL. Retroauricular hairline incision for removal of upper neck masses. The Laryngoscope 2005;115:21612166.

21.Ikeda Y, Takami H, Niimi M, Kan S, Sasaki Y, Takayama J. Endoscopic thyroidectomy by the axillary approach. Surgical endoscopy 2001;15:1362-1364.

22.Monfared A, Saenz Y, Terris DJ. Endoscopic resection of the submandibular gland in a porcine model. The Laryngoscope 2002;112:1089-1093.

23.Selvadurai D, Wildin C, Treharne G, Choksy SA, Heywood MM, Nicholson ML. Randomised trial of subcuticular suture versus metal clips for wound closure after thyroid and parathyroid surgery. Annals of the Royal College of Surgeons of England 1997;79:303-306. 24.Cooke M, Talbot JC, Branfoot T. 'Neck-line' incision for open reduction and internal fixation of the clavicle. Annals of the Royal College of Surgeons of England 2009;91:437-438. 